\title{
KONSEP MANUSIA DALAM SISTEM PENDIDIKAN ISLAM
}

\author{
Dinasril Amir \\ Dosen Fakultas Tarbiyah IAIN Imam Bonjol Padang \\ e-mail:dinasril_amir@yahoo.co.id
}

\begin{abstract}
Education concept closely relates to humans' concept themselves. How humans' concept will relate to their concept on education because the education itself is an effort to direct humans' concept. Islamic concept on education is a holistic unit. This paper describes the humans' concept that has dignity, well in nature, multidimentional, and multipotential. Thus, the Islamic education attempts to direct students become selfconfidence, creative and innovative in developing their capabilities. New education system in Islam is determined by new concept on Islamic thinking.
\end{abstract}

\begin{abstract}
Abstrak: Konsep pendidikan berhubungan erat dengan konsep manusia itu sendiri. Bagaimana konsep seseorang tentang manusia begitulah konsepsinya tentang pendidikan, karena pendidikan itu adalah usaha untuk mewujudkan manusia yang dikonsepsikan. Konsepsi Islam tentang manusia dalam pendidikan bersifat holistik. Di dalam makalah dijelaskan konsep manusia yang memiliki hakikat yang mulia, harkat dan martabat yang tinggi serta konsep manusia yang bersifat multidimensional dan multipotensial. Oleh karena itu upaya pendidikan dalam Islam hendaklah berusaha seoptimal mungkin untuk mewujudkan hakikat kemanusiaan peserta didik serta mengangkat harkat dan martabat mereka, di samping meluaskan dimensi kehidupan dan mengembangkan potensi. Sistem baru pendidikan dalam Islam ditentukan oleh konsep baru (new) manusia dalam pemikiran Islam.
\end{abstract}

Kata Kunci: manusia, pendidikan, hakikat, harkat, martabat, multi dimensional dan potensial.

\section{PENDAHULUAN}

Dalam keilmuan pendidikan ada lima bagian pokok pendidikan yang penting dikaji dan dipelajari, yaitu konsep tentang manusia, tujuan pendidikan, peserta didik, pendidik, dan proses pembelajaran.(Prayitno, 2009: 6-20). Yang sangat pokok dan substansial dari kelima komponen keilmuan pendidikan ini adalah konsep tentang manusia, karena manusia adalah makhluk yang dapat dididik (peserta didik) dan bisa mendidik (pendidik) serta kepadanya proses pembelajaran dan tujuan pendidikan dimaksudkan dan ditujukan, sedangkan makhluk lain selain manusia tidak bisa melakukannya, sehingga dengan itu manusia dijuluki dengan sebutan homo educabile, (Abd. Rachman Assegaf, 2011: 164) di samping julukan manusia modern (homo sapiens, homo recens). (Widyadara, 2005: 54) Homo sapiens adalah salah satu organism hidup yang paling berhasil dalam evolusi dan kedudukannya di alam semesta, karena memiliki otak yang besar dan cerdas, pengamatan dan telaah yang baik, pandai berbahasa, berjalan tegak dan bertangan terampil, pandai membuat dan memakai peralatan, mempunyai organisasi sosial, mampu bertani, menjinakkan dan memelihara, serta mampu mengubah daerah sekitar sehingga layak untuk tempat tinggal. Pada aspek ini manusia adalah makhluk yang memiliki kemanusiaan manusianya (hakikat, dimensi dan potensi kemanusiaan) yang dapat menjadi objek dan subjek pendidikan serta sumber pendidikan itu sendiri bagi pengembangan diri. Pendidikan harus berpijak pada kemanusiaan yang dimiliki oleh manusia, karena kemanusiaan manusia itu tidak akan bisa berkembang tanpa adanya pelayanan pendidikan terhadapnya. Bukankah pendidikan itu, tidak lain dan tidak bukan adalah usaha manusia untuk memuliakan kemanusiaan manusia. (Prayitno, 2009: 1). Oleh sebab itu, kajian tentang konsep pendidikan tidak bisa dipisahkan dengan kajian tentang konsep manusia. Bagaimana konsep orang tentang manusia begitu pulalah pada umumnya konsepsi mereka tentang pendidikan, karena 
pendidikan itu tidak lain adalah usaha mewujudkan konsep manusia yang telah dikonsepsikan. Menurut Louis O. Kattsoff : "Sesungguhnya bentuk pemerintahan dan pendidikan sangat begantung pada pandangan kita tentang manusia, karena manusia itulah yang menjadi unsur yang amat pokok dan penting dari pendidikan."(Yahya Jaya, 1993: 34) Jadi, antara pendidikan dan manusia itu ibarat dua sisi mata uang yang satu, di mana kalau tidak ada satu sisi maka uang itu tidak laku dan tidak bisa menjadi alat pembayaran. Maksudnya pendidikan itu tidak akan laku kalau upayanya tidak bertujuan memuliakan manusia.

Dewasa ini kajian tentang manusia dengan segala hakikat, dimensi dan potensinya tetap amat penting serta menarik untuk dilakukan dan dikembangkan. Hal itu disebabkan karena faktor sumber daya manusia (SDM) yang cerdas dan kompetitif adalah pokok bagi kemajuan suatu umat atau bangsa, di samping faktor sumber daya alam (SDA). Misalnya dalam pandangan sosiologi modernisme ditegaskan bahwa pesatnya pertumbuhan ekonomi pada bangsa-bangsa maju berkaitan erat dengan kualitas manusia yang mereka miliki. Malah pertumbuhan ekonomi masa depan banyak ditentukan oleh faktor SDM, seperti yang sudah dibuktikan oleh Jepang yang miskin SDA, akan tetapi termasuk sebagai bangsa yang maju dan modern di dunia, karena memiliki kekayaan SDM yang berkualitas berkat sistem filsafat pendidikan dan kehidupan yang mereka anut. Filsafat pendidikan Jepang antara lain berintikan pandangan tentang persamaan potensi manusia (equality), belajar sepenuh waktu (study full time), kerja keras (try harder), serta motivasi dan semangat yang tinggi (bushido). (Yahya Jaya, makalah, 20 Agustus 2003). Di samping itu pandangan orang terhadap seseorang ditentukan oleh bagaimana persepsi dan konsepsinya tentang seseorang itu (manusia). Kalau seseorang pendidik itu mempersepsikan dan mengkonsepsikan peserta didiknya kayak benda (pahat) dan mesin yang tidak punya kebebasan dan atau manusia yang punya kebebasan, maka ia akan memberlakukannya kayak demikian. Kalau ia mengkonsepsikan manusia kayak pahat, maka ia akan memberlakukan peserta didik kayak pahat, seperti dipukul lebih dahulu maka baru bisa jalan. Kalau kayak mesin diservis (dihidupkan) lebih dahulu maka baru bisa jalan. Kalau manusia dipersepsikan sebagai makhluk yang memiliki kebebasan dalam tindak dan kehendak, maka ia akan memuliakan manusia itu dalam pelayanan pendidikan. Agama Islam dengan sistem pendidikannya sangat memperhatikan soal harkat dan martabat manusia serta peningkatan kualitas SDM seperti dapat dilihat dari pengertian pendidikan dan konsep manusia yang ada dalam Islam.

Mengikut Prayitno, bahwa pendidikan itu bermacam-macam tetapi hakikatnya satu, yaitu usaha memuliakan kemanusiaan manusia. (Prayitno, 2009: 1) Menurut pengertian ini jelas bahwa objek kajian dan sasaran pendidikan itu adalah manusia, baik sebagai persona maupun masyarakat. Manusia yang menjadi objek kajian dan sasaran pendidikan itu menurut konsepsi psikologi adalah manusia yang memiliki motivasi dan abilitas psikologikal untuk berubah dan belajar, maju dan berkembang serta mengembangkan dimensi dan potensi kehidupannya seoptimal mungkin. Menurut Abraham H. Maslow bahwa manusia sebagai individu memiliki motivasi dan abilitas yang besar untuk berubah dan belajar dan ia adalah orang yang paling tahu tentang dirinya. That the individuals have the motivation and ability to change, and are the best expertise themselves. Oleh karena pendidikan dan psikologi sama-sama mengkaji manusia, maka terdapat hubungan yang erat antara keduanya serta psikologi menjadi salah satu asas pendidikan dalam Islam. Kalau konsep pendidikan berhubungan erat dengan image tentang manusia, maka konsep psikologi juga berhubungan erat dengan konsep tentang manusia. Hubungan yang erat ini bisa dimaknai bahwa konsep tentang manusia harus duduk dan jelas lebih dahulu dalam sistem pendidikan maupun psikologi Islam agar pelayanan pendidikan dapat berjalan dengan efektif dan efisien serta membawa kepada capaian pembentukan insan cerdas dan kompetitif. Sama halnya dengan psikologi bahwa das Sollen pendidikan Islam itu adalah terletak pada citra baru kita tentang manusia, new psychology is new image of man. 
Dalam rangka mendapatkan new Islamic education (pendidikan Islam dalam arti cita dan ideal seperti yang diteladankan Nabi, baru, das sollen), maka dalam makalah ini dibahas konsep pendidikan Islam tentang manusia seperti yang terdapat dalam Alquran dan hadis serta sebagaimana yang berkembang dalam filsafat dan pemikiran Islam. Kemudian, konsep manusia tersebut dikaitkan dengan konsep pendidikan yang dikehendaki oleh ajaran Islam, karena konsep tentang manusia berhubungan erat dengan konsep tentang pendidikan sebagai yang telah dijelaskan di muka. Kelemahan selama ini (das sein) adalah dunia pendidikan Islam mengabaikan konsep Islam tentang manusia dalam sistem dan pelayanan pendidikan, sehingga pelayanan pendidikan Islam yang dilaksanakan selama ini terkesan kurang memuliakan manusia alias kurang menyentuh hakikat manusia, serta meluaskan dan mengembangkan dimensi dan potensi manusia. Sesunggguhnya bagaimana konsep Islam tentang manusia begitulah pula konsep kita tentang pendidikan Islam, karena pendidikan itu pada hakikatnya tidak lain adalah usaha untuk mewujudkan dan memuliakan manusia yang kita konsepsikan. Pengabaian pengetahuan dan pemahaman tentang konsep manusia berarti pengabaian kesejatian tentang konsep pendidikan itu sendiri, karena kegiatan pendidikan berasal dari manusia, untuk manusia dan dilakukan oleh manusia dalam rangka pendekatan diri kepada Tuhannya, Allah SWT, sebagai abdi-Nya.

\section{PEMBAHASAN}

Konsep manusia dalam Islam terletak pada harkat dan martabat manusia dalam Islam. Harkat dan martabat manusia dalam Islam dapat pula dilihat dari hakikat manusia, dimensi dan potensi yang dimiliki oleh manusia itu sendiri yang dapat dijelaskan sebagai berikut:

\section{HAKIKAT MANUSIA DALAM ISLAM}

Kaum Materialisme Antropologik memandang hakikat manusia semata-mata atas materi; bahwa manusia adalah jasad yang tersusun dari bahan-bahan material dari dunia anorganik. Kaum Materialisme Biologik berpendapat bahwa manusia adalah badan yang hidup. Sedangkan kaum Idealisme Antropologik memandang manusia sebagai makhluk yang memiliki kehidupan spiritual-intelektual yang intrinsik dan tidak tergantung pada materi. Dalam perspektif Islam pandangan ini belumlah lengkap, karena kedudukan manusia di mata Allah SWT dan di alam jagad sungguh mulia dan tinggi. (Hassan Shadily, 1983: 2139).

Hakikat manusia dalam Islam dapat dijelaskan sebagai berikut. Pertama, manusia adalah makhluk yang paling baik. Manusia adalah ciptaan Allah SWT yang baik (indah, the best) bentuk kejadiannya di antara makhlukmakhluk yang ada di alam semesta ini sehingga dijuluki Alquran surat al-Tiin (85) dengan insan ahsani taqwiim dan tetapi bisa pula jatuh kepada asfala saafiliin. Ahsani taqwiim dalam pengertian bahwa manusia memiliki derajat yang lebih tinggi secara jasmani dan rohani bila dibanding dengan makhluk lainnya. Dari segi jasmani kelebihan dan kesempurnaan manusia terletak pada bentuk ciptaan fisik dan rupa wajahnya yang sangat indah dan sempurna, serta ditambah dengan posisi badannya yang tegak lurus ,ke atas. Dan dari segi rohani, manusia adalah makhl;uk yang berbudaya dan berkekuatan spiritual keagamaan, karena manusia memiliki kemampuan akal dan kalbu yang tidak dimiliki oleh makhluk lain. Ahsani taqwiin juga berarti orang yang beriman dan bertakwa serta pandai bersyukur kepada Allah SWT. Sedangkan pengertian asfala saafiliin antara lain adalah kesesatan dan orangnya bertempat di neraka kelak, karena ia tidak beriman, ingkar dan tidak bersyukur kepada Alah SWT, tidak seperti orang yang ahsani taqwiim. (Mahyuddin Khazanah, Nomor 60: 724) Kedua, manusia sebagai makhluk yang paling sempurna (insan kamil). Manusia dalam Islam juga dikenal dengan sebutan insan kamil dengan potensi jasmani, akal, kalbu, akhlak, sosial dan seni serta dimensi,psikologikal yang dimilikinya. (Zakiah Daradjat, 1992: 23-34) Ketiga, manusia sebagai makhluk khalifah di muka bumi. Keberadaan manusia di bumi adalah berfungsi sebagai khalifah yang bertugas memakmurkan penduduknya. Oleh karena itu segala wujud psikologikal dan kesehatan mentalnya di bumi harus sesuai dengan apa yang diajarkan Allah SWT dalam 
agama-Nya, seperti difilterisasi dan disesuaikan dengan prinsip, tujuan dan kaidah-kaidah yang terdapat dalam syariat Islam. Keempat, manusia sebagai makhluk yang paling bagus proses kejadiaanya. Menurut Alquran surat AlMukminun (23) ayat 12-16 manusia diciptakan Allah dari intisari tanah yang dijadikan nutfah (sperma bagi laki-laki dan ovum atau telur bagi wanita) dan disimpan di tempat yang kokoh dan aman. Kemudian nutfah (campuran antara sperma laki-laki dan perempuan) dijadikan darah beku, darah beku dijadikan mudhgah, mudhgah (zighot) dijadikan tulang ('izhaam), tulang dibalut dengan daging (lahm), yang kemudian dijadikan Allah makhluk manusia dalam bentuk fisik (al-basyar). Inilah 5 periode kejadian manusia dalam Alquran. Kelima, makhluk yang bersifat ke-Tuhanan (rohani). Dalam surat al-Hijr (15) ayat 29 dan As-Sajadah (32) ayat 7-9 selanjutnya menjelaskan bahwa setelah kejadian manusia dalam kandungan mengambil bentuk al-basyar, ditiupkan ke dalamnya roh (ciptaan-Ku) dan dijadikan baginya pendengaran, penglihatan, dan perasaan, sehingga lengkaplah proses kejadian manusia sebagai manusia khalifah yang memiliki banyak kemuliaan. Dalam hadis yang diriwayatkan oleh Imam Bukhari dan Muslim lebih lanjut lagi menyebutkan bahwa roh ditiupkan Allah SWT ke dalam fisik janin setelah ia mengalami perkembangan 40 hari nutfah, 40 hari 'alaqah (darah beku) dan 40 hari mudhgah. (M. Rasyid Ridha, 1342: 24) Keterangan Alquran dan hadis ini dapat berarti bahwa Allah SWT memberi manusia potensi berupa sifat-sifat dan akhlakakhlak-Nya seperti yang terdapat dalam asmaul husna, sehingga manusia betul-betul memiliki sifat ke-Tuhanan. (Hasan Langgulung, 1991: 361) Keenam, manusia sebagai makhluk yang mulia. Dalam surat al-Isra' (17) ayat 70 ditegaskan oleh Allah bahwa manusia adalah makhluk yang mulia dengan kemuliaan berupa kemudahan dalam penguasaan ilmu pengetahuan dan teknologi, rezeki dan kelebihan-kelebihan lain dari makhluk lain. (Mahyuddin Khazanah, Nomor 60: 26) ---dan ayat-ayat Alquran lain tentang kemukjizatan ilmiah Alquran tentang manusia baca QS 51: 20-21, 41: 53, 29: 43, 95: 4, 19: 9, 27: 88, 41: 53, 3: 191, 39: 6, 71: 13-14, 23: 12-13, 80: 17-
19, 76: 2, 32: 7-8, 86: 5-6, 16: 4, dan 96: 1-5. --Jadi, konsep manusia menurut Alquran dan hadis adalah makhluk jasmani dan rohani, atau materi dan immateri dalam arti luas. Unsur jasmani yang berasal dari tanah di bumi, dan unsur ruh yang berasal dari substansi immateri di alam gaib. Unsur jasmani pada akhirnya akan kembali menjadi tanah, dan rohani akan kembali pula ke alam gaib yang menjadi milik dan kekuasaan Allah SWT sebagai dikatakan Alquran dalam surat al-Fajr (89) ayat 27-30 berikut. Hai nafsu mutmainah ! Kembalilah kepada Tuhanmu (Allah SWT) dengan hati yang ridha dan diridhai-Nya. Lalu masuklah ke dalam golongan hamba-hamba-Ku dan surga$\mathrm{Ku}$.

Konsepsi tentang hakikat manusia Islam menurut Alquran dan hadis (homo Islamicus) di atas, kemudian berkembang dalam sejarah pemikiran dan filsafat Islam. Misalnya dalam falsafat Islam dikenal manusia itu sebagai makhluk multidimensional dan multipotensional. Manusia sebagai makhluk multidimensional setidak-tidaknya memiliki 7 dimensi (aspek) dalam kehidupannya. Sedangkan manusia sebagai makhluk multipotensial memiliki banyak potensi baik (fitrah) dalam kehidupannya.

\section{MANUSIA SEBAGAI MAKHLUK MULTI- DIMENSIONAL}

Dalam Islam memiliki 7 dimensi dalam dalam kehidupan, yaitu jasmani, rohani, akidah, sosial, akhlak, akal, dan estetika.

1. Dimensi jasmani.

Dimensi jasmani diakui Islam eksistensinya karena jiwa dibutuhkan badan agar dapat melaksanakan fungsi-fungsi dan tugasnya. Tanpa bantuan badan jiwa tidak akan dapat melaksanakan fungsi dan tugasnya seperti berpikir, merasa, dan bertindak. Pada hakikatnya dalam kehidupan di dunia ini bukan badan yang butuh kepada jiwa, akan tetapi jiwalah yang amat membutuhkan badan. Buktinya hewan dapat hidup tanpa jiwa (akal). Oleh karena jiwa amat membutuhkan badan, maka kualitas jasmani manusia harus ditumbuhkembangkan dengan seoptimal mungkin dalam hidupnya agar dia berdaya guna dan berhasil 
guna bagi kehidupan rohani manusia. Dimensi jasmani melukiskan konsep manusia sebagai sosok al-basyar.

2. Dimensi Rohani/Spiritual Keagamaan

Dimensi rohani (spiritua keagamaanl) adalah pokok dan sentral dari kehidupan manusia. Menurut Alquran setelah proses taswiyah dari bentuk fisik kejadian manusia lengkap, kemudian Allah meniupkan ruhNya sebagai tanda kesempurnaan kejadian manusia, seperti dikemukan surat al-Hijir (15) ayat 28-29. Menurut Al-Kindi : Jiwa itu berhubungan dengan Tuhan seperti hubungan cahaya dengan matahari. Jiwa manusia berhubungan dengan imej dan aspek (shuurah) ke-Tuhan Allah SWT ditegaskan pula oleh Nabi Muhammad SAW dalam hadis berikut: InnaAllaaha khalaqa Aadam 'alaa shuuratihi. Sesungguhnya Allah SWT menciptakan Adam sesuai dengan citra-Nya (memiliki spirit rohaniah yang berasal dariNya). Spritualitas rohaniah manusia itu adalah tiupan fitrah Allah SWT kepada manusia. Tiupan fitrah dalam arti potensi (cahaya) dan dimensi ketuhanan dari-Nya untuk manusia serta yang akan kembali juga nanti kepada-Nya. Innaa Lillaahi wa Innaa Ilaihi Raaji'un. Menurut al-Ghazali dalam Ihyaa' 'Uluumiddiin jiwa itu adalah hakikat hakiki manusia, karena jiwalah yang patuh atau durhaka kepada Allah. Jiwa sebagai hakikat manusia memiliki daya dan potensipotensi dalam kehidupannya, seperti daya takwa, cipta, rasa, karya, dan karsa. (Yahya Jaya, 1993: 36) Potensi dan daya-daya jiwa itu butuh pengembangan, kalau tidak manusia akan statis dan pasif. Kebutuhan manusia kepada pengembangan jiwa (takwa) itulah mungkin yang dimaksud oleh John Naisbitt dengan spirituality, keinginan akan spiritualitas hidup atau sebuah pengalaman spirirtual dalam kehidupan manusia yang tak terpisahkan dengan keagamaan, sebagai lawan kehidupan duniawi dan sensual yang tidak menjamin kebahagiaan manusia selama ini. Kemungkinan itu ada alasannya karena psikologi yang berkembang dalam dunia ilmu pengetahuan dewasa ini tidak banyak mengkaji soal tingkah laku manusia dalam kaitannya dengan dimensi dan potensi manusia yang ada, seperti spiritual keagamaan. Pengembangan dimensi dan potensi ini dalam Islam melukiskan konsep manusia sebagai sosok al-ins dalam Alquran surat al-Dzariyat (51) ayat 56 dan pada dimensi ini pula lah maksud utama Allah SWT menjadikan manusia. Aku tidak menciptakan jin dan manusia kecuali agar mereka beribadah kepada-Ku.

3. Dimensi 'akidah.

Pada hakikatnya tiada seorang pun manusia ini yang ateis, karena dimensi akidah (agama, ketuhanan) sudah ada pada setiap manusia sebelum ia dilahirkan ke bumi, sekalipun ia bukan dilahirkan dari seorang ibu yang non-Islam. Menurut Alquran surat al-A'raaf (7) ayat 172: Manusia sebelum dilahirkan ke dunia telah mengucapkan sumpah setia (miistaq) dengan Allah dan mengakui Allah sebagai Tuhannya, alastu birabbikum qaalu balaa syahidnaa. Dalam pandangan Islam keperluan kepada agama adalah fitrah dan tabiat manusia yang pokok. Didapati manusia tidak beragama dan ateis pada hakikatnya adalah penyimpangan saja karena Allah telah menjadikan agama itu sebagai salah satu dimensi kehidupan dan keperluan manusia yang amat pokok. Alquran menegaskan dalam surat al-Rum (30) ayat 30 bahwa manusia hendaklah menghadapkan wajah dengan lurus kepada agama (Islam) yang sesuai dengan fitrah Allah SWT karena disebabkan Dia telah menciptakan manusia menurut fitrah-Nya itu, yakni beragama dan berakidahkan tauhid. Tidak ada perubahan pada ciptaan Allah itu, serta itulah agama yang lurus, tetapi kebanyakan manusia tidak mengetahui. Dalam hadis ditegaskan pula oleh Nabi Muhammad SAW bahwa setiap manusia dilahirkan adalah dalam fitrah Allah dan lantas karena kedua orang tua (lingkungan) merekalah yang menyebakan mereka menjadi Yahudi, Nashrani dan Majusi. Maa min mauluudin illaa yuuladu 'alal fitrati, fa'abawaahu yuhauwidaanihi au yunashshiraanihi au yumajjisaanihi. Dengan alasan ini dapat lagi digarisbawahi pendapat John Naisbitt dan pakar lainnya yang mengatakan bahwa dasawarsa tahun 90-an 
yang lalu dan abad XXI ini adalah abad kebangkitan agama dari millenium baru. Alasan lain dari kebangkitan agama adalah karena agama itu adalah fitrah dan keperluan (needs) jiwa manusia yang paling tinggi. Dalam agama ada psikologikal dan spiritual, material dan immaterial, kecerdasan, kesehatan dan kebahagiaan, harkat dan martabat manusia, serta dalam agama derajat dan martabat manusia dimuliakan dan ditinggikan. Pentingnya dimensi akidah keimanan dalam kehidupan manusia juga diakui oleh Albert Einstein, William James, dan Carl Gustav Jung. Einstein mengatakan bahwa ilmu tanpa agama lumpuh dan agama tanpa ilmu buta. James mengatakan pula bahwa iman adalah obat yang paling mujarab bagi banyak penyakit dalam kehidupan manusia. Sedang Jung mengatakan pula bahwa iman adalah penolong bagi manusia dalam mengatasi masalah dan gangguan kejiwaannya. Islam sebagai suatu sistem teologi dan sivilisasi yang komplit bagi kehidupan manusia di dunia dan akhirat kelak memiliki potensi dan kemungkinan yang sangat besar sekali bagi pengembangan dimensi akidah (belief) itu dalam kehidupan manusia ke arah yang baik dan benar, karena akidah tauhid itu adalah asas segala-galanya. Pengembangan dimensi akidah/agama ini melukiskan konsep manusia sebagai al-ins dan makhluk agamais.

4. Dimensi sosial.

Setiap manusia dilahirkan menjadi salah seorang anggota kelompok sosial, man is born a social being. Dengan demikian manusia adalah makhluk sosial. Seandainya manusia tidak memiliki dimensi sosial dalam hidupnya, niscaya umat manusia sudah punah di bumi ini, karena manusia dilahirkan dalam keadaan lemah sekali serta sangat membutuhkan bantuan sosial lingkungannya untuk bisa bertahan hidup, seperti orang tua. Dimensi sosial dalam kehidupan manusia juga ditekankan Islam. Misalnya dengan adanya ajaran Islam tentang keadilan sosial dan memandang ibu-bapak sebagai sahabat yang paling baik. Malah dalam suatu hadis ada ditegaskan oleh Nabi Muhammad SAW bahwa surga itu terletak di bawah telapak kaki ibu-ibu. Al-Jannatu tahta aqdaamul ummahaat. Hadis ini pada hakikatnya adalah hadis yang berhubungan dengan pendidikan yang menunjukkan besarnya tanggung jawab sosial ibu-ibu terhadap anak-anak mereka dalam bidang pendidikan. Pengembangan dimensi sosial melukiskan konsep manusia sebagai sosok an-naas.

5. Dimensi akhlak.

Akhlak merupakan pula salah satu dimensi pokok dalam kehidupan manusia menurut Islam. Oleh karena itulah Allah mengutus Muhammad SAW menjadi nabi dengan tugas utama memperbaiki akhlak manusia. Dalam hal ini Nabi Muhammad SAW menegaskan: "Sesungguhnya aku diutus menjadi rasul adalah bertujuan untuk memperbaiki akhlak manusia." Bu'itstu liutammima shaalihal akhlaaq. Dalam hadis lain dikatakan untuk memuliakan akhlak. Innamaa bu'itstu liutammima makaarimal akhlaaq. Kalau dilihat dari konsep akhlak yang terdapat dalam Islam dan kedudukan akhlak dalam kehidupan manusia dapat dimengerti dasar filosofis dari ucapan itu. Pertama masalah akhlak itu adalah masalah kemanusiawian yang erat hubungannya dengan jiwa sebagai hakikat hakiki manusia. Kedua pengertian akhlak itu yang luas bidangnya dalam kehidupan manusia. Dalam Al-Quran konsep akhlak itu tidak saja terbatas pengertiannya dalam kehidupan pribadi (al-akhlaaql fardiyah) dan keluarga (al-akhlaaql usrah), akan tetapi juga meliputi penataan hubungan baik manusia dalam kehidupan sosial (al-akhlaaqul ijtima'iyah), politik (al-akhlaaqul daulah), dan keagamaan (al-akhlaaqud diiniyah). Atau pada penataan hubungan baik manusia dalam hablun minallah dan hablun minannas, akan tetapi juga meliputi hablun minal alam, hablun minannafsi, dan hablun minal jismi. (Yahya Jaya, 1993: 36) Kesejahteraan dan kebahagiaan hidup manusia dalam keseluruhan dimensi dan potensi kehidupannya itulah tujuan pendidikan akhlak dalam Islam. Oleh karena itu akhlak dalam Islam menjadi penentu kualitas, harkat, dan martabat manusia. Semakin tinggi tingkatan akhlak manusia, semakin 
tinggi tingkatan kualitas, kebahagiaan, dan kesempurnaan hidupnya, serta semakin mulialah harkat dan martabatnya.. Dengan demikian sistem akhlak Islam dan ditambah dengan ajaran tasawufnya dapat memenuhi kebutuhan hidup manusia di bidang akhlak, etika, dan moral, serta dalam mengatasi masalah-masalah kemanusiaan masa kini dan mendatang. Jadi ucapan Nabi Muhammad SAW tentang makaarimal akhlaaq atau shaalihal akhlaaq memiliki dasar filosofis yang dalam dan implikasi yang luas dalam kehidupan manusia. Pendeknya kalau akhlak sudah mulia, kesehatan jiwa akan diperoleh, kebahagiaan akan dicapai, kesempurnaan akan dirasakan, serta pada akhirnya manusia dapat berhubungan dan bersatu dengan Allah. Pengembangan dimensi akhlak ini melukiskan konsep manusia sebagai sosok 'ibaadullah.

6. Dimensi akal.

Akal adalah satu-satu dimensi kehidupan yang meninggikan manusia dari malaikat dan hewan karena dengannya kualitas manusia menjadi bertambah tinggi dan kedudukannya semakin unik di bumi. Dipilihnya Adam AS (manusia) sebagai khalifah Allah di bumi, mengalahkan malaikat, adalah karena manusia memiliki akal yang dengannya manusia dapat memiliki kualitas di bidang ilmu pengetahuan dan teknologi serta seni untuk mengelola dan memakmurkan dunia. Manusia khalifah itu dalam Islam kualitasnya tidak saja ditentukan oleh nilai akhlak ('ibaadah) yang dimilikinya, akan tetapi juga ditentukan oleh kualitas ilmu (siyaadah). Oleh karena itulah Islam sangat menghargai akal dan memuliakan kedudukannya. Dalam agama Islam ditegaskan bahwa agama itu adalah akal dan tidak ada agama bagi orang yang tidak memiliki akal. Addiinu huwal 'aqlu laa diina liman laa 'aqla lahu, dan ungkapan ini ada yang mengatakan hadis Nabi Muhammad SAW. Dalam Alquran banyak sekali ayatayat yang berhubungan dengan fungsi akal dan suruhan supaya orang mempergunakan akal atau pikiran sehatnya, seperti dalam ucapan afalaa ta'qiluun dan afalaa tatafakkaruun. Kalau dilihat dalam sejarah pemikiran Islam kelihatan ketinggian kedudukan akal dalam kehidupan umat Islam zaman kalsik. Misalnya dalam teologi Islam terkenal adanya aliran teologi rasional seperti teologi Muktazilah dan Muhammad Abduh, serta dalam falsafat Islam ungkapan yang mengatakan bahwa manusia adalah makhluk yang berpikir. Pada hakikatnya sikap rasional seperti yang terdapat teologi Muktazilah dan Muhammad Abduh, serta pemikiran dan tasawuf falsafi seperti yang terdapat dalam falsafat dan tasawuf Islam adalah wujud manusia sebagai makhluk yang berpikir dalam Islam. Pada hakikatnya sikap rasional dan sifat-sifat lainnya yang menjadi ciri utama masyarakat modern sudah ada dasardasarnya dalam ajaran Islam, malah sudah dimiliki dan dibuktikan oleh umat atau ulama Islam zaman klasik, sayang orang Islam banyak yang tidak menyadarinya. Kalau umat Islam dewasa ini memiliki visi yang baik dan benar tentang Islam maka ia akan dapat merasakan bahwa Islam itu sesuai dengan segala zaman dan tidak akan sesaat dan menyesatkan karena hal demikian sudah menjadi jaminan Nabi SAW. Taraktu fiikum amraini maa in tamassaktum bihimaa lan tadhilluu abadaa, kitaab Allah wa sunnata rasuuluh. Dalam pengembangan dimensi akal ini ajaran Islam memiliki potensi dan sumber motivasi yang besar bagi manusia untuk berkembang, karena ajarannya banyak bersifat rasional. Misalnya dalam teologi ada teologi rasional, syariah ada mazhab hanafi, dan dalam sivilisasi ada dorongan yang tinggi kepada umatnya untuk menuntut ilmu. Pengembangan dimensi akal ini melukiskan konsep manusia sebagai sosok al-unaas. (Harun Nasution, 1981: 3-23)

7. Dimensi estetika.

Ajaran Islam tidak membantah adanya dimensi estetika (seni) dalam kehidupan manusia dan nilainya cukup tinggi dari nilai politik. Dalam Islam banyak ajaran yang berhubungan dengan dimensi estetika dalam kegiatan manusia. Misalnya dalam hadis dikatakan bahwa Allah itu indah dan suka kepada keindahan, serta ucapan yang mengatakan bahwa kebersihan dan kesucian itu sebagian dari keimanan. Inna Allah 
jamiilun yuhibbul jamaal, al-nadzaafatu minal iimaan. Arti dari semua ucapan Nabi Muhammad SAW itu, tidak lain adalah bahwa ajaran Islam menyuruh umatnya untuk hidup bersih, suci, tertib, indah, dan mencintai aktivitas-aktivitas kesenian dalam kehidupan manusia sebagai cara untuk memenuhi keperluan dimensi estetikanya. Pengembangan dimensi estetika itu dalam Islam dituntut kepada manusia untuk dikembangkan sebatas kemampuannya. Untuk itu semua karya seni harus berangkat dari etika keagamaan dan untuk keagamaan Islam. Dalam Islam seni bukan untuk seni melainkan seni untuk kehidupan agama manusia sehingga dengan demikian hidup terasa indah, besih, dan tertib, diri merasa cantik, serta perasaan menjadi halus. Kalau dipelajari sejarah kebudayaan Islam zaman klasik ternyata nilai seni yang ada dalam Islam tak kalah dari agama dan kebudayaan yang lain karena dapat melahirkan karya seni yang besar seperti yang terdapat di Granada, Cordova, Samarkand, Taskent, Iran, Turki, dan Timur Tengah. Kalau John Naisbitt dan Patricia Aburdene meramalkan masa akan datang sebagai masa kebangkitan dalam kesenian. Untuk ini Islam tidak mengingkarinya karena seni itu adalah salah satu dimensi dari kehidupan manusia. Nilainilai yang ada dalam Islam bisa dijadikan pedoman dan tuntunan dalam kebangkitan kesenian sehingga memunculkan seniman. Prinsip seni dalam Islam bukanlah seni untuk seni sehingga menjadikan orang senewen, akan tetapi menjadikan seni untuk peningkatan harkat, martabat, kebahagiaan, dan kualitas hidup manusia. Pengembangan dimensi estetika ini melukiskan konsep manusia sebagai sosok yang indah dan halus.

Ketujuh dimensi atau aspek kemanusiaan itu yang juga merupakan kepribadian manusia dalam Islam harus bertumbuhkembang dalam keseimbangan, kesatuan ikatan, serta saling melengkapi dan menyempurnakan di antara satu dan lainnya dan tidak boleh ada yang terabaikan atau paling diunggulkan. Semua harus dimuliakan dan mendapatkan pengembangan yang optimal serta tidak boleh terjadi pengekangan sehingga kemanusiaan manusia berkurang. Jadi, manusia multidimensional itu adalah manusia dalam konsep makhluk jasmani, rohani/spiritual, agamis, sosial kemasyarakatan, seni, akhlak/kejiwaan, dan akal. Manusia multidimensional menampilkan sosok manusia dalam konsep al-basyar, alinsaan, an-nas, al-unaas, al-ins, 'ibaadullaah, ahsani taqwiin, khalifah Allah di bumi, insan kamil (manusia paripurna, manusia seutuhnya) serta halus dan indah. Pengakuan manusia sebagai makhluk multidimensional merupakan basic needs dalam sistem pendidikan Islam. Tanpa pengakuan itu pendidikan Islam akan kehilangan identitasnya yang asli dan kebahagiaannya yang sejati. Kesempurnaan kepribadian dan kebahagiaan manusia multidimensional tidak hanya terletak pada pemenuhan keperluan jasmani, akan tetapi juga terletak pada pemenuhan keperluan jiwa, agama (akidah), sosial, akhlak, akal, dan seninya. Dialah konsep manusia khalifah, insan kamil, insan saleh, manusia seutuhnya, manusia yang sesuai citranya dengan Allah, ahsani taqwiim, 'ibaadullaah, mulia, agung, serta manusia yang bahagia dunia-akhirat dan terpelihara dari azab neraka dalam Islam. Manusia harus berusaha menyempurnakan dimensi-dimensi kehidupannya agar menjadi insan kamil. Manusia itu merupakan makhluk multidimensional yang harus menangkap berbagai fenomena yang juga bersifat multidimensional. Ketika dimensidimensi manusia itu komplit (insan kamil), maka ia akan berkemampuan dalam merespons fenomena yang ada dengan tepat. Sebaliknya, kalau persoalannya menunjukkan bahwa fenomena yang ada jauh lebih banyak dibanding dengan kemampuan yang dimiliki manusia, maka akibatnya solusi menghadapi fenomena yang terjadi tidak sempurna. Kalau konsep manusia dalam Islam merupakan makhluk multidimensional, maka konsep pendidikan dalam Islam harus juga bersifat miltidimensional agar pas dan pasti.

\section{MANUSIA SEBAGAI MAKHLUK MULTI- POTENSIAL}


Manusia sebagai makhluk Allah SWT dianugerahkan-Nya potensi yang banyak sekali jumlahnya. Fitrah atau potensi baik itu adalah dalam bentuk akhlak dan sifat-sifat Allah yang agung sebagai yang terkandung dalam asmaaul husnaa. Asmaaul husnaa merupakan potensi yang dikaruniakan Allah kepada manusia yang wajib ditumbuhkembangkan melalui kegiatan pendidikan Islam. (Hasan Langgulung, 1991:361-363) Pada umumnya jenis akhlak dan sifat-sifat Allah itu dimiliki oleh manusa karena Allah memang telah menciptakannya kepada manusia di mana ciptaan itu tidak akan diubah lagi seperti yang dimaksud surat Ar-Ruum ayat 30 di muka. Misalnya Allah memiliki sifat wujud, kuasa, mencipta (kreatif), dan ilmu, manusia juga memiliki sifat-sifat demikian, kendatipun tidak sama kualitasnya. Tugas dan tujuan manusia dalam hal ini adalah mengembangkan potensi-potensi baik tersebut sebatas kemampuannya sebagai manusia melalui pelayanan pendidikan Islam yang disertai dengan rasa amanah (bertanggung jawab). Manusia memang memiliki kemungkinan untuk menumbuh-kembangkan potensi-potensi itu seoptimal mungkin, tetapi tidak akan mampu menandingi sifat-sifat keMaha-an Allah. Kalau manusia memaksakan juga, itu namanya tidak amanah dan melampaui batas serta bisa mengundang timbulnya kebinasaan. Misalnya, dalam kehidupan seperti apa yang dialami oleh Fir'aun dalam pengembangan sifat kuasanya sehingga ia mendakwakan dirinya sebagai Tuhan yang wajib disembah, dan akhirnya ia mengalami kebinasaan. Pengembangan potensi sebatas kemampuan dan amanah yang dibebankan kepada manusia itulah makna ibadat dalam arti luas, serta itu pula makna pendidikan dalam Islam. Jadi, manusia itu memang unik dan istimewa dengan potensi-potensi yang dimiliki dan dikembangkannya. Inilah lagi mungkin yang dimaksud oleh hadis Nabi Muhammad SAW yang mengatakan bahwa Allah menjadikan Adam AS sesuai dengan citra-Nya. Inna Allah khalaqa Aadam alaa shuuratihi. Itu pulalah artinya manusia sebagai makhluk multipotensial. Kalau konsep manusia dalam Islam merupakan makhluk multipotensial, maka pendidikan hendaklah pula upayanya dimaksudkan untuk mengembangkan potensi akhak dan sifat-sifat Allah SWT yang dimiliki umat agar pas dan pasti.

Dari pembahasan yang telah dilakukan pada fasal A, B, dan C dapat ditegaskan bahwa konsep manusia dalam pendidikan Islam adalah manusia yang berhakikatkan potensi keTuhanan, berharkatkan ketinggian derajat, dan bermartabatkan kemuliaan kemanusiaan. Konsep manusia semacam ini adalah juga konsep insan saleh, insan kamil atau manusia seutuhnya dalam Islam yang menjadi tujuan pelayanan pendidikan. Konsep ini adalah pula konsep manusia yang seimbang dalam partumbuhan dan perkembangan kepribadiannya secara total yang didapat melalui pelatihan jiwa, semangat, motivasi dan kekuatan spiritual keagamaan serta intelektual, rasionalitas diri, emosional, sosial, dan kepekaan rasa tubuh. Dengan dimikian pendidikan diarahkan untuk mengembangkan manusia dalam segala hakikat, dimensi dan potensinya, baik secara individual maupun kelompok, serta mendorong semua pengembangan itu untuk mencapai kebaikan dan kesempurnaan. Tujuan akhir pendidikan Islam diarahkan pada upaya merealisasikan pengabdian manusia kepada Allah SWT, baik pada tingkat individual maupun masyarakat dan kemanusiaan secara luas. (BP MAFIKIBB ICMI, 2010: 30) Dalam bahasa pendidikan nasional konsep manusia semacam ini dapat pula dikatakan sebagai konsep SDM yang cerdas dan kompetitif.

Konsep Islam tentang manusia sebagai makhluk yang berhakikat, berharkat dan bermartabat di atas tidaklah dapat dikatakan sebagai suatu cita-cita khayali yang mustahil diwujudkan. Konsep itu pernah wujud dalam zaman klasik sejarah Islam. Konsep tersebut logis karena demikianlah kenyataannya manusia dan kehidupan masyarakat Islam di masa Nabi Muhammad SAW dan zaman keemasan Islam klasik. Walaupun das sollen manusia multidimensional dan multipotensial tidak mungkin terwujud seoptimal mungkin bagi setiap individu, akan tetapi dalam konteks masyarakat harus diwujudkan seoptimal mungkin dan merupakan fardu kifayah hukumnya. Masyarakat Islam sebagai umat harus mengembangkan dimensi-dimensi dan potensi-potensi tersebut 
seoptimal mungkin sehingga dengan demikian umat dapat menjawab tantangan-tantangan peradaban abad XXI dan memenuhi harapanharapannya. Sebagai persona minimal hakikat, dimensi-dimensi dan potensi-potensi itu harus tetap ada dan menunjukkan eksistensinya dalam kehidu-pan manusia walaupun kadarnya agak rendah. Kalau salah satu dimensi dan potensi kemanu-siaan itu tidak mendapatkan pengembangan sebagaimana mestinya dan malah sampai hilang dalam kehidupan, maka berarti manusia mempersempit diri dan kebahagiaannya dengan sistem pendidikan yang dilaksanakannya.

Terwujudnya konsep manusia mulidimensional dan multipotensial di atas sudah barang tentu meminta sejumlah persyaratan. Apakah itu persyaratan yang bersifat internal maupun eksternal. Di antara persyaratan internal adalah will (kemauan kuat, kebulatan tekad) dari umat Islam sendiri untuk mewujudkan, membangkitkan, atau menumbuhkembangkan nilai-nilai keislaman dalam segala aspek kehidupan menuju kebangkitan Islam kembali. Bukankah kebangkitan Islam kembali yang didengungdengungkan sejak abad XX sampai abad XXI M itu pada hakikatnya terletak pada kemampuan umat Islam dalam membangkitkan nilai-nilai keislaman itu sendiri dalam segala aspek dan aktivitas kehidupan. Misalnya, nilai-nilai keimanan (maa huwal iimaan) yang menyangkut dengan keyakinan, pengetahuan, kemauan, dan kondisi jiwa, nilai-nilai keislaman (maa huwal islaam) yang menyangkut dengan sikap dan tingkah laku, serta nilai-nilai keihsanan (itqaan) (maa huwal ihsaan) menyangkut dengan pengembangan hubungan komunikasi dan interaksi manusia dengan Tuhan dan lingkungannya. (M. Rasyid Ridha, 1342: 8-15).

\section{MANUSIA DAN PENDIDIKAN DALAM AJARAN ISLAM}

Perlu ditegaskan kembali secara filosofi bahwa perspektif pendidikan berhubungan erat dengan upaya pembentukan dan perwujudan manusia dan masyarakat, karena yang dikaji oleh pendidikan itu adalah juga manusia dan masyarakat. Bagaimana gambaran manusia dan masyarakat yang kita cita-citakan begitu pulalah bentuk pendidikan yang hendak direncanakan, karena manusia dan masyarakat itulah yang menjadi unsur yang amat pokok dan penting dari sistem dan kegiatan pendidikan Islam.

Bertitik tolak dari dasar pemikiran di atas maka bentuk pendidikan yang kita susun hendaklah pula mengacu kepada image manusia dan masyarakat yang dicita-citakan Islam yang bersifat hakiki, multidimensional dan multipotensial itu. Dalam dunia psikologi ada semboyan yang mengatakan bahwa new psychology is new image of man, semboyan ini tentu berlaku pula dalam dunia pendidikan Islam. Dengan kata lain pendidikan Islam sebagai sarana untuk mengkaji dan mewujudkan masa depan umat Islam yang cerah, maka filosofi kajian dan implementasinya hendaklah berbentuk usaha memotivasi manusia untuk mau berubah dan belajar, maju dan berkembang, serta mau menemukan hakikat diri, meluaskan dimensi kehidupan dan mengembangkan potensi diri seoptimal mungkin, sehingga dengan itu umat dapat mengatasi masalahnya dan menjawab tantangan zaman serta merasakan kebahagiaan dunia dan akhirat plus terpelihara dari azab neraka di dunia maupun akhirat. Rabbanaa aatinaa fid dunyaa hasanah wafil akhirati hasanah waqinaa 'adzaaban naar. Kebahagiaan dunia dalam arti keadaan yang baik dan optimal dalam kehidupan dunia berupa peroleh nikmat, afiat dan taufik dari Allah SWT. Kebahagiaan akhirat dalam arti kondisi yang baik dan selamat di dalam kehidupan akhirat kelak berupa rahmat, ihsan dan keselamatan (alnajaah) yang diperoleh. Taqiyah (terpelihara) dari azab neraka dalam arti bebas dari siksaan, gangguan dan azab yang ada di dunia dan akhirat. (Dinasril Amir, 2005: 97) Pendidikan Islam jangan hanya dipahami sebagai upaya pembentukan pengetahuan, akan tetapi lebih daripada itu adalah usaha memotivasi manusia untuk mau berubah dan belajar, maju dan berkembang, serta usaha meluaskan dimensi kehidupan dan potensi diri seoptimal mungkin, baik sebagai persona maupun masyarakat, sehingga menemukan hakikat diri. Karena hidup itu menuntut perubahan dan pembelajaran, kemajuan, perjuangan (jihad) dan pembangunan, serta perluasan dimensi dan pengembangan potensi diri seoptimal mungkin. Alquran dengan tegas-tegas mengingatkan bahwa Allah SWT 
tidak akan mengubah nasib (kehidupan) suatu kaum, kalau kaum itu tidak mau mengubah nasibnya. Inna Allaaha laa yughaiyiru maa biqaumin hattaa yughaiyiru maa bi anfusihim. Sesungguhnya kehidupan itu adalah akidah dan jihad perjuangan. Kegiatan-kegiatan pendidikan Islam hendaklah ditujukan kepada perbaikan dan peningkatan kualitas hidup manusia sebagai makhluk multidimensional dan multipotensional, sehingga kegiatan pendidikan dapat mewujudkan manusia khalifah dan insan saleh (kamil) yang menjadi dambaan Islam. Jadi jelasnya, mesti ada aktivitas pendidikan Islam yang memotivasi manusia dalam mengem-bangkan dimensi jasmani, rohani, akhlak, sosial, akidah, akal, dan estetika, serta mengem-bangkan potensi (fitrahnya) dalam segala aspeknya. Dengan kata lain pendidikan Islam hendaklah mampu memotivasi umat dalam mewujudkan manusia Islam, yaitu makhluk jasmani (albasyar), spiritual (al-ins), sosial (annaas), rohani atau kejiwaan (al-insaan), berakal (alunaas), beragama ('ibaadullah), dan berestetika (jamiil). Dalam kaitannya dengan pembenahan lembaga pendidikan Islam maka harus ada upaya dan persepsi pendidikan Islam untuk mengembangkan konsep pendidikan yang holistik atau dalam bentuk pendidikan yang multidimensional dan multipotensial tersebut. Dalam hubungan dengan pengertian ini maka isu-isu dan kegiatan yang menyangkut dengan ekonomi (penghapusan kemiskinan), kejiwaan (kesejukan hati), sosial, seni-budaya, pengembangan pendidikan dan ilmu pengeta-huan serta industrialisasi (mengejar keterbe-lakangan dan membasmi kebodohan) adalah penting diangkat menjadi tema-tema pendidikan Islam.

Kalau dunia Islam mau menjadikan pendidikan sebagai sarana untuk mewujudkan manusia dan masyarakat multidimensional dan multipotensial dalam Islam, maka mereka harus berani melakukan kebijakan Islamisasi dunia ilmu pengetahuan, pendidikan, dan kehidupan bermasyarakat Islam. Apakah itu dalam bentuk mengubah sistem dan pola pelayanan pendidikan dari apa yang berlaku sekarang, misalnya dengan mengubah kurikulum pendidikan Islam. Dalam perubahan kurikulum penekanannya hendaklah ditekankan pada usaha mengubah kondisi material, membangun sumber daya manusia, serta mengembangkan dimensi dan potensi individu dan masyarakat, ataupun dari orientasi yang tidak seimbang antara kehidupan dunia dan akhirat menjadi seimbang dan harmonis. Pendeknya perluasan dan pengembangan persepsi, wawasan, orientasi, materi, fungsi, peranan, sifat, tema, sistem, metode, taktik dan strategi, serta pendekatan pendidikan Islam di zaman yang menjunjung tinggi HAM (hak asasi manusia) dan HMM (harkat dan martabat manusia) ini perlu diperbaharui kembali (semacam usaha tajdid) terhadap lembaga-lembaga pendidikan dengan memanfaatkan kemajuan ipteks yang diasimilasikan dengan keimanan dan ketakwaan (imtak), sehingga dengan demikian dapat diatasi masalah, dihadapi tantangan, dan dipenuhi harapan umat Islam. Kalau tidak Era Globalisasi dan Industrialisasi hanya akan membuat umat lupa kepada Allah SWT dan agama-Nya, merusak HAM dan HMM, menjadi beban dan masalah bagi kehidupan manusia (tidak menjadi rahmat), serta menjadi ancaman bagi kehidupan sosial-budaya umat. Bukankah pendidikan Islam itu dalam persepsi dan orientasinya bertujuan untuk mengantarkan manusia menjadi manusia Islam yang senantiasa mendapatkan kebahagiaan dan kesejahteraan hidupnya di dunia dan akhirat serta terpelihara dan terbebas dari azab neraka dengan menekankan keseimbangan antara kualitas ipteks dan imtak dalam kehidupan manusia sebagai makhluk multidimensional dan multipotensial.

\section{SIMPULAN}

Dari uaraian yang telah dikemukakan di atas dapat ditarik beberapa kesimpulan sebagai berikut.

1. Bahwa konsep pendidikan dalam Islam tidak bisa dipisahkan pengertiannya dengan konsep manusia Islam (homo Islamicus), karena pendidikan itu adalah usaha untuk mewujudkan konsep manusia yang dicitacitakan Islam. Konsepsi Islam tentang manusia adalah makhluk multidimensional dan multipotensional, maka makhluknya pendidikan itu dalam Islam hendaklah pula dikembangkan makna dan sifatnya yang multidimensional dan multipotensional. Pendidikan Islam dapat diartikan sebagai 
upaya memotivasi manusia dalam bertingkah laku terhadap kebaikan dan huda serta amar makruf dan nahi mungkar yang ditujukan untuk mencapai kebahagiaan (psychological well being) di dunia dan akhirat serta terbebas dan terpelihara dari penyakit dan sengsara azab neraka.

2. Pengertian pendidikan tidak dapat dipisahkan dari konsep tentang manusia dan masyarakat serta peradaban, maka lembaga-lembaga pendidikan Islam harus memiliki konsep yang jelas, pas dan pasti tentang manusia dan masyarakat serta peradaban yang dikembangkan dalam kegiatan pendidikan, sehingga dengan demikian mudah menyampaikan nilai-nilai pendidikan dan pembudayaan. Dalam hal ini peta psikologi keberagamaan (Islam) manusia baik sebagai persona dan masyarakat serta peta medan dan perencanaan pendidikan harus dibuat, dimiliki, dan dikembangkan terus secara simultan. Manusia dan masyarakat dalam Islam adalah makhluk yang bersifat multidimensional dan makhluk multi potensial.

3. Kalau lembaga-lembaga pendidikanIslam mau mewujudkan apa yang menjadi harapan umat Islam masa datang serta mengatasinya dari masalah dan tantangan yang menghadang, maka dari sekarang lembagalembaga pendidikan Islam haruslah pandaipandai menjabarkan konsep pendidikan Islam yang bersifat hakikional, multidimensional dan multipotensial itu terhadap manusia dan masyarakat Islam serta menggalakkan dan mengembangkan investasi di dunianya. Oleh karena pendidikan itu adalah investasi untuk semua (education for all), maka dukungan dan investasi dari semua pihak dalam pengkonsepsian dan perwujudan pendidikan yang demikian harus pula diusahakan serta diyakini dukungan dan investasi dari semua pihak (all for Islamic education). Umat itu mengikut keyakinan para pemimpin mereka, an-naas 'alaa diini muluukihim. Manusia Islam, masyarakat Islam dan peradaban Islam hanya terwujud melalui mekanisme pelayanan pendidikan Islam yang unggul.

\section{DAFTAR RUJUKAN}

Abuddin Nata, 2010. Ilmu Pendidikan Islam, Jakarta: Prenada Media Group

Aulia, 1974. Agama dan Kesehatan Jiwal Badan, Jakarta: Bulan Bintang

Darraaz, M. Abdullah, 1982. Dustuurul Akhlaaq Fil Quran, Kairo: Daarul Buhuutsul Ilmiyah

Dinasril Amir, 2005. Islam \& Pendidikan Kesehatan Mental: Pemikiran Hasan Langgulung, Padang: The Minangkabau Foundation

Al-Faruqi, Ismail Ragi, 1982. Islamization of Knowledge, Maryland: International Institute of Islamic Thought

Al-Ghazali, 1980. Ihyaa' 'Uluumud Diin, Beirut: Dasrul Fikri

Hambal, Ahmad bin, Musnad al-Iman Ahmad bin Hambal, Beirut: Maktabah Islami.

Honigmann, John J. 1959. The World of Man, New York: Harper \& Row Publishers

Ka'bah, Rifyal, $2002 . \quad$ "Dakwah Multidimensional", Makalah, disampaikan dalam Seminar Nasional Dewan Dakwah Indonesia Daerah Sumatera Barat di Padang

Kattsoff, Louis O., 1986. Elements of Philosophy, alih bahasa Soejono Soemargono "Pengantar Filsafat", Yogyakarta: Tiara Wacana

Kompas, 1990. Menuju Masyarakat Baru Indonesia, Jakarta: Gramedia

Langgulung, Hasan, 1988. Pendidikan Islam Menghadapi Abad 21, Jakarta: Alhusna , 1980. Beberapa Pemikiran Tentang Pendidikan Islam, Bandung: al-Maarif , 1986. Manusia dan Pendidikan, Suatu Analisa Psikologi dan Pendidikan, Jakarta: Alhusna 1991. Kreativitas dan Pendidikan Islam, Jakarta: Pustaka al-Husna

LP. IAIN Jakarta, 1982. Seminar Islam Mengadapi Tantangan Zaman Kini dan Mendatang, Jakarta: IAIN 
M. Anis Matta, 2006. Model Manusia Muslim Abad XXI: Pesona Manusia Pengemban Misi Peradaban Islam, Bandung: Progresio

Nasution, Harun, 1983. Falsafat \& Mistisisme Dalam Islam, Jakarta: Bulan Bintang 1981. Konsep Manusia Menurut Ajaran Islam, Jakarta: LP IAIN

Ridha, M. Rasyid, (ed.), 1342. Majmu'atul Hadis, Medinah: Pustaka Salafiah

Rifai, Bachtiar TB., 1980. Uraian Himak Isra' dan Mikraj, Jakarta; Yayasan Idayu

Hassan Shadily (ed.),1983. Ensiklopedi Indonesia 4, Jakarta: Ichtiar Baru-Van Hoeve

Yahya Jaya, 1990. Islamisasi Psikologi dan Kesehatan Mental, IAIN Padang: Pidato Dies 1991. "Pemantapan Peran dan Fungsi Lembaga-Lembaga Dakwah dalam Menghadapi Era Globalisasi Informasi", Makalah, disampaikan dalam "Diskusi Panel" Dewan Dakwah Indonesia Perwakilan Sumatera Barat, tanggal 9 Maret 1991 di Bukittinggi.

1993. Spiritualisasi Islam dalam Menumbuhkembangkan Kepribadian dan Kesehatan Mental, Jakarta: Ruhama

Widyadara, 2005. Ilmu Pengetahuan Populer, Jakarta: Grolier Internassional, Inc.

Zakiah Daradjat, 1984. Kesehatan Mental Peranannya Dalam Pendidikan dan Pengajaran, Jakarta: LP IAIN Jakarta 